\title{
Fog attenuation penalty analysis in terrestrial optical wireless communication-modified duo-binary return-to-zero system with various receiver pointing errors
}

\author{
Mustafa H. Ali' ${ }^{1}$, Tariq A. Hassan ${ }^{2}$, Hiba A. Abu-Alsaad ${ }^{3}$ \\ ${ }^{1}$ Department of Basic Sciences, College of Dentistry, Mustansiriyah University, Baghdad, Iraq \\ ${ }^{2}$ Department of Computer science, College of Education, Mustansiriyah University, Baghdad, Iraq \\ ${ }^{3}$ Department of Computer Engineering, College of Engineering, Mustansiriyah University, Baghdad, Iraq
}

\begin{tabular}{l} 
Article Info \\
\hline Article history: \\
Received Mar 5, 2021 \\
Revised Nov 29, 2021 \\
Accepted Dec 2, 2021 \\
\hline
\end{tabular}

Keywords:

Atmospheric attenuation

Fog

Modified duo-binary return-to-

zero

Optical wireless

Communications pointing errors

\begin{abstract}
In metropolitan communication infrastructures a revolutionary technique is emerge known as terrestrial optical wireless communication (OWC), which makes a high-rise building connection is possible. Even with this solution, there are many other problems like the influence of haze and fog in the propagation channel which obstruct and scatter OWC propagation light and consequently led to a big attenuation, due to propagate in temporal, angular and spatial of the light signal. Not to mention the minimum visibility that discourages the implementation of the pointing errors (PE) and tracking system. This present work aims to analyze the interrelation between multiple scattering (dense fog, heavy fog, light fog, heavy haze and light haze) and receiver PE under modified duo-binary return-to-zero (MDRZ) system. We found that PE caused by beam swag is the main controlling factor and industriously minimize the link margin, signal-to-noise ratio (SNR), and raise the bit error rate (BER) when there is an increasing the turbulence strength and the track length. We recommended to guarantee transmitterreceiver alignment by installing a variable field of view (FOV) receiver (a tracking system) to overcome the scattering impact of the fog that make render urban laser communication effective in the presence of PE.
\end{abstract}

This is an open access article under the CC BY-SA license.

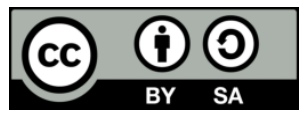

\section{Corresponding Author:}

Mustafa H. Ali

Department of Basic Sciences, College of Dentistry, Mustansiriyah University

Baghdad, Iraq

Email: mustafa.h@uomustansiriyah.edu.iq

\section{INTRODUCTION}

Until 1962 radio-frequency $(\mathrm{RF})$ consider appropriate communicating securely between satellite and submarine, but after this year a new laser technology is appearing that replace the RF uses point to point space communication systems this replacement is happen duo to low risk of electromagnetic interference (EMI), lower power requirement and higher bandwidth capacity [1]. Fog which considers the most challenging attenuator and have remained a research topic for optical wireless communication (OWC) links over the years. Fog may have distinguished by many physical elements, i.n. humidity, temperature, particle size distribution and liquid water content [2]-[7].

In real time There is an increasing transmission requirement for high data rate and only optical communications can provide this bandwidth required. In spite of fiber backbone extend hither and thither in the world and reached greatest cities in the globe and yet are discouraged by bottleneck that limit data flow through "the last mile," reaching the end user. Recently the wireless term has been conveniently linked with 
technologies like the RF, led to the rise of terrestrial OWC that was emerging in the telecommunication industry as a viable source for providing a great important modification in the scope of communication technology in general [8]-[11]. Terrestrial OWC was Initially taken into account at a resolution of the last mile access trouble that happened when internet service provider (ISP) cannot link optical fiber from the central office $(\mathrm{CO})$ to every user residence duo to the high installation costs. Therefore, the investigations are in the way of increasing data transfer speed applications by enabling connecting link between two fixed platforms for example companies, business office and other targeted facility locations through free space optical (FSO) atmospheric channel and by wherewithal of minimum light emitting diodes (LEDs) or lasers [12], [13], without conceding the effectiveness parameters and resource expense of spreading by the fiber optic connection as shown in the Figure 1.

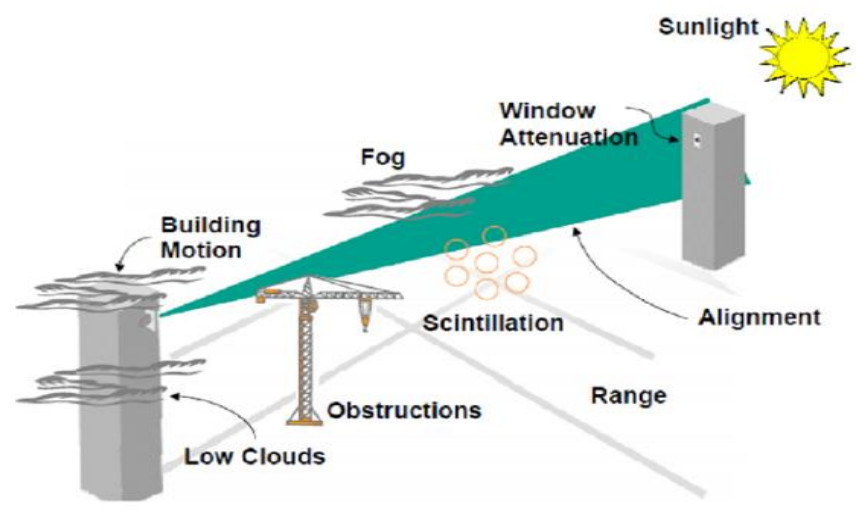

Figure 1. Graphical explanation of the Terrestrial OWC scenario [14]

OWC usually utilizes modulated beams of infrared or visible light to send some very big data volumes among line of sight (LOS) transceivers. The frequency ranges of 20-300 $\mathrm{THz}$ in the optical carrier produce a hungry communication application for the future of OWC links technology. The major applications of OWC include short, mid and long range communication applications when there is a need to transmit high data volumes (100 GB/s range) [15], [16].

The main condition of making a successful connection and establish a communication link in the terrestrial OWC outdoor area is the condition of point to point communication, in other word we need a very clear line of sight over a range up to several kilometers between the receiver and transmitter. To do so and neglect the requirement of any optic fiber cable [17]. We need to use invisible beams of light having up to 20 Gbps data rate, to supply optical bandwidth linked authorize video communications, data and voice altogether on air, the system depended of an optical receiver and optical transmitter suppling a bi-directional ability at the time the free space work as the connecting channel [18]. On the other hand, OWC system has two main disadvantages that its effectiveness relies on it, which give rise to transmission errors.

Firstly, Mie scattering phenomena is the major attenuation participating impact that brings about 480 $\mathrm{dB} / \mathrm{km}$ attenuations in dense maritime fog environments in La Turbie (France) and $130 \mathrm{~dB} / \mathrm{km}$ in continental fog climate in Graz (Austria) [19]. This is a phenomena (Mie scattering) mainly occurs duo to spatial difference in the complex refractive index real part, during transmitting wavelength. Which in turn happened because of the statistical fluctuations in fog particle density as shown in Figure 2 [20]-[22].

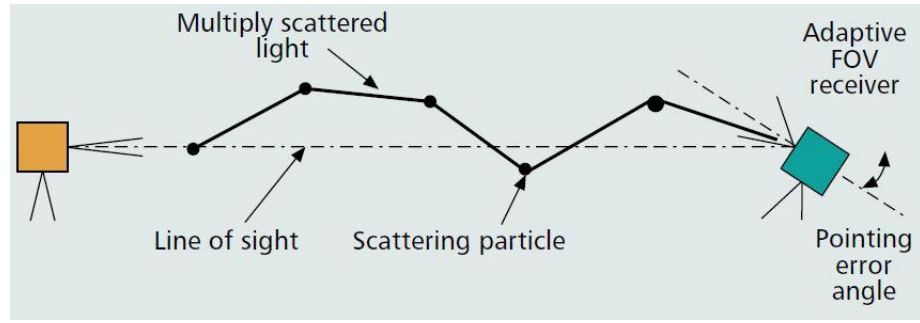

Figure 2. Schematic illustration in the presence of multiple scattering medium and pointing error [23] 
Secondly, misalignment fading that happened with Weak earthquakes in the building sway phenomenon, dynamic wind loads and Thermal expansion that reason of shaking the transmitter beam driving to a misalignment among receiver and transmitter recognized as pointing error as shown in Figure 3. These PE may lead to important effectiveness degradation and are a critical problem in civilized region, because the terrestrial OWC devices are located in high rise buildings [24]-[27].

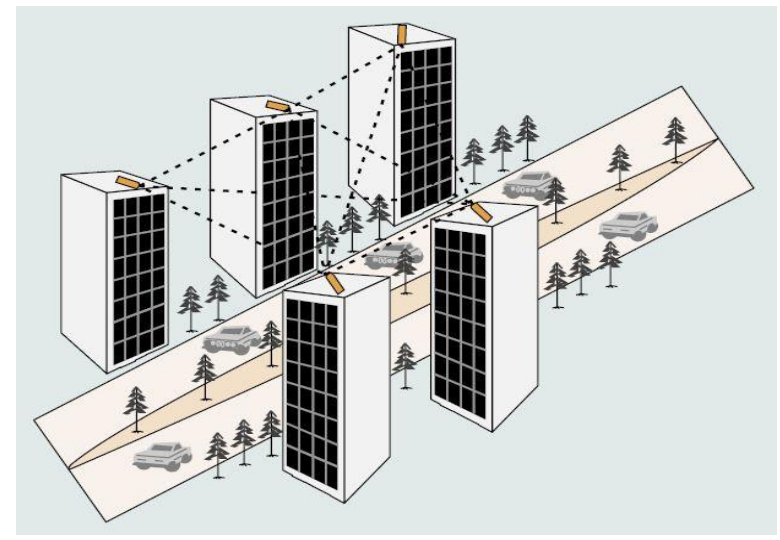

Figure 3. OWC transceiver system located on high rise buildings within 100-5000 m range

Most recent studies take into their consideration and suppose that influence of single-scattering in the signal in the received side has no ISI, and that is correct in case light fog situation [28]. In our article we discuss this problem and analysis them in an optisystem program to come up with the best recommendation, therefore many solutions have come to surface to hold line-of-sight among the receiver and transmitter, like they must raise the beam width and power. Even that, a wide beam width raises the wanted SNR directing to raise the intricacy and estimate price, additionally, outage appearances might consequence in case of narrow beam [29]. Another solution has raised as the laser power increased to overcome the extra attenuated as the distance raised. As a consequence of difference in the refractive index, Turbulence-induced fading happened, that, familiar as scintillation, which give rise to irradiance fluctuations in the signal on the other side. We already know that the return-to-zero (RZ) modulation format is best for long distance, even with it is complex and costly comparing to non-return-to-zero (NRZ), which is employed for short range. Therefore, we concentrate on other modulation techniques to analysis like below some recent paper that discusses recent problems near to our topic.

Balaji and Prabu [30] using orthogonal frequency division multiplexing (OFDM) the authors investigate the performance of radio-on-free space optical (ROFSO) system scheme. The result shows as we increase hops (L) total link length of the ROFSO system is enhanced significantly. Also, with hybrid direct current-biased optical orthogonal frequency division multiplexing-pulse width modulation (DCO-OFDMPWM) and direct current-biased optical orthogonal frequency division multiplexing- position modulation (DCO-OFDM-PPM). Schemes in [31] show that the cellular order provides marginally bigger BER achievement against the LOS link. Ebrahimi et al. [32] is another paper study the DCO-OFDM-PPM for an ideal LOS channel and for 16- QAM at the BER of 10-3. While [33] studied The Monte Carlo simulations idea of a variable field of view receiver of different optical and densities types for narrow-beam in OWC, the result shows the possibility of boosting communication system effectiveness through fog in a simple and cheap way. on other hand [34] introduce insight into designing effective FSO systems that present measurement results in the southern coast of France, the conclude shows better performance and enhanced resilience.in addition, the proposed system [35] is designed for wavelength division multiplexing (WDM) using 64 channels. It is observed from the results that modified duo-binary return-to-zero-differential quadrature phase-shift keying (MDRZ-DQPSK) modulation gives excellent Q-factor compared to dark return-to-zero (DRZ)-DQPSK and carrier-suppressed return-to-zero (CSRZ)-DQPSK Modulation with data rate transmission equal to $10 \mathrm{Gbps}$ in a favorable distance up to $4500 \mathrm{~km}$. Now in [36] the authors trying to reduce pointing errors by replacing the multi-hop relay configuration via an equivalent dual-hop scheme to used it in the 5G/5G+ networks. And finally, Gappmair and Nistazakis [37] we are extending this study to a gamma-gamma model, the results provide approximate closed form expressions, which are accurate enough over a wide signal to noise ratio range. Chauhan et al. [38] the binary phase-shift keying (BPSK) FSO link combined with the $2 * 2$ space diversity technique gives enhance BER effectiveness of $42 \%$ compared to onoff keying (OOK) these techniques can merge a collection of devices into smart cities. 


\section{THE PROPOSED METHOD}

During different atmospheric attenuation impacts on the OWC communication link, fog is the extreme significant parameter. The best delicate method of attenuation counting in droplet fog condition, is founded by Mie scattering low. Even that, Mie scattering low requested particular knowledge of fog factor, for example refractive index, particle size distribution, and particle size. That might not be easily obtainable at a specific position of designation. Furthermore, it includes a complicated calculation. On the other hand, a proposition is predicting a particular attenuation according to the use of fog data clarity. Here we discussed Kruse and Kim models. These models utilize clarity to predict particular attention. The particular attenuation model for both Kruse and Kim are given by (1) and (2).

$$
a_{\text {spec }}=\frac{10 \log V \%}{V(k m)}\left(\frac{\lambda_{0}}{\lambda}\right)^{-q}(\mathrm{~dB} / \mathrm{km})
$$

For Kruse model $\lambda_{0}$ as visibility, reference $(550 \mathrm{~nm}), \lambda$ in $\mathrm{nm}$ stands for wavelength, $\mathrm{V} \%$ stands for transmission of the air drops to percentage of clear sky and $\mathrm{V}(\mathrm{km})$ stands for visible.

$$
q=\left\{\begin{array}{cc}
1.6 & \text { if } V>50 \mathrm{~km} \\
1.3 & \text { if } 6 \mathrm{~km}>V>50 \\
0.585 V^{1 / 3} & \text { if } V<6 \mathrm{~km}
\end{array}\right\}
$$

In (2) means that, there will be minimum attenuation for bigger wavelengths for any meteorological situation. We anticipated the attenuation of $1550 \mathrm{~nm}$ is less than the attenuation of shorter wavelengths. Below Kim model for low visibility in dense fog which explain reject this wavelength conditional attenuation. The q variable in the (1) for is given by the (3):

$$
q=\left\{\begin{array}{cc}
1.6 & \text { if } V>50 \mathrm{~km} \\
1.3 & \text { if } 6 \mathrm{~km}<V<50 \mathrm{~km} \\
0.16 V+0.34 & \text { if } 1 \mathrm{~km}<V<6 \mathrm{~km} \\
V-0.5 & \text { if } 0.5 \mathrm{~km}<V<1 \mathrm{~km} \\
0 & \text { if } V<0.5 \mathrm{~km}
\end{array}\right\}
$$

Kruse and Kim model is expressed when the general attenuation coefficient that work as a function of wavelength and visual range as given by (4):

$$
a(\lambda)=\frac{3.912}{V}\left[\frac{\lambda}{550}\right]\left[1^{q} / k m\right]
$$

According to the model (3), $\mathrm{q}$ is the size distribution of scattering particles, $\lambda$ is the wavelength in nanometers is the visibility distance in kilometers and $\alpha(\lambda)$ is the specific attenuation the attenuation $\gamma$ of fog and finally haze is regarding to permeability by the (5) where $\alpha$ is the coefficient of attenuation for every unit of length, $\mathrm{P}(0)$ is the emitted power and $\mathrm{P}(1)$ is the power of the signal at a range 1 of the sender.

$$
\tau(l)=\frac{P(l)}{P(0)}=e^{-a * l}
$$

Suppose that fog deploy in the entire communication rang to cover a distance, to simulate the minimal absorption, the imaginary part must be one thousandth of the real part. Using the Kruse formula in fog let us distinguish its situation with a visibility distance and impute fog to the optical attenuation. However, this Kruse format is unsuitable to fog duo to fog wavelength dependence is very small in the infrared range and visible. And this led to, it is very substantial to allocate a fog situation with an element that is very comprehensive than a vision ranges, thus let us to use $1550 \mathrm{~nm}$ wavelength in our design. Now we discuss the type of modulation used in our design, which is modified duobinary (MDB) scheme that include two-digit correlation interval. Compressing bandwidth in the MDB is imaginable because of it is schematic design. We chose modified duo-binary return-to-zero (MDRZ) in our simulation design duo to MDRZ format has a very narrow optical bandwidth comparing to regular duo-binary return-to-zero (DRZ) and thus make MDB has high fiber non linearity and great dispersion tolerance. Duobinary (DB) and MDB are shown by (6), (7) respectively, explaining the pulse forms.

$$
\begin{aligned}
& x(t)=\sin c\left(\frac{t}{y}\right)+\sin c\left(\frac{t-T}{T}\right) \\
& x(t)=\sin c\left(\frac{t+T}{T}\right)-\sin c\left(\frac{t-T}{T}\right)
\end{aligned}
$$




\section{RESEARCH METHOD (SIMULATION)}

OWC collection made up of 3 requisite components: the receiver, the atmospheric channel, and sender. OWC also recognized as "lasercom," that turn into a reality of life recently in the field of civilized high demand wireless networks. The transmitter includes a telescope that aligns and collimates the beam transport the optic signal. And a laser that is modulated to diffuse pulses. Our propagation channel system is the atmosphere in urban terrestrial applications the receiver and transmitter are located on the rooftops of bridges, high rise buildings within 100-5000 $\mathrm{m}$ range as shown in the Figure 3.

As shown in block Figure 4, it needs 2 optical modulators earn MDB signal; first one to raise the transmitter expense by carve the NRZ data to RZ signal and the second one is to generate NRZ duo-binary signal. The Figure 5 explain the simulation of the $20 \mathrm{Gbps}$ MDB in optisystem program. It is identical to duo-binary RZ, especially in the first step that generate the a NRZ duobinary signal, although there is a delay and add a circuit replaced by delay subtract circuit.

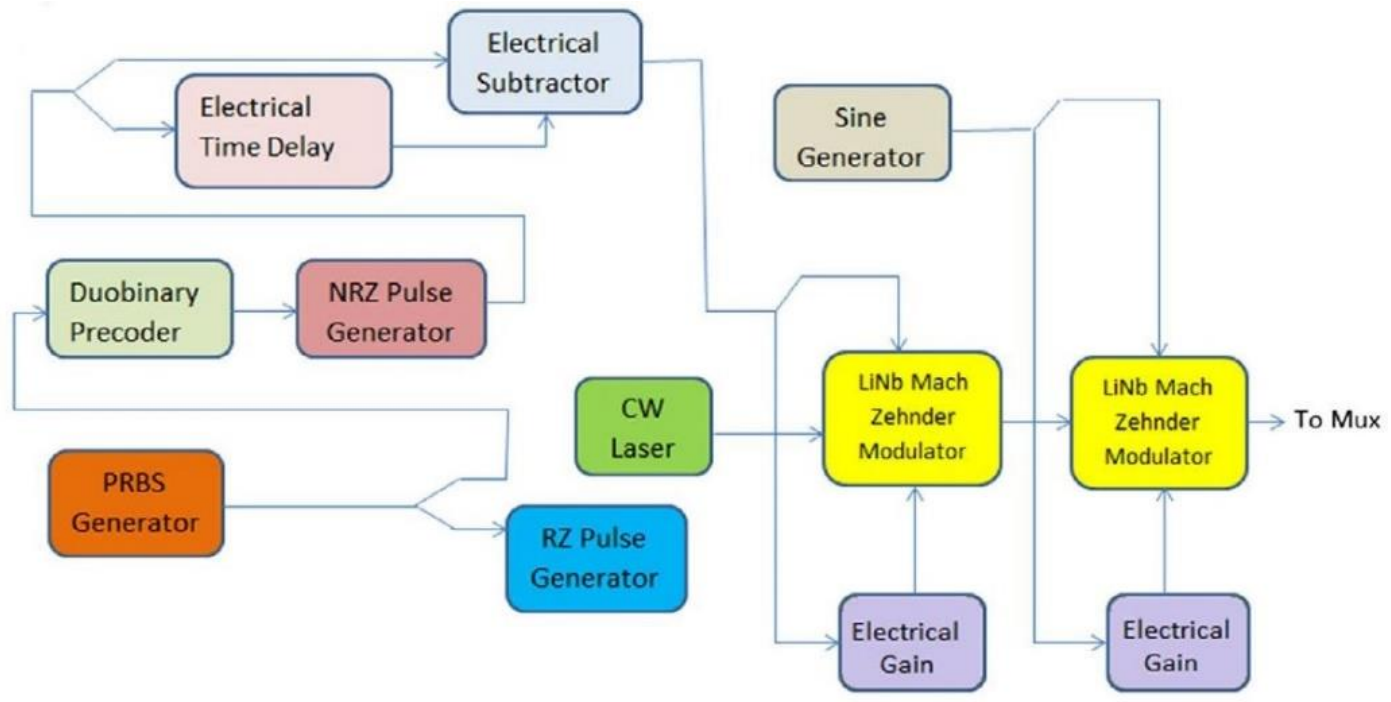

Figure 4. Block diagram of MDRZ transmitter

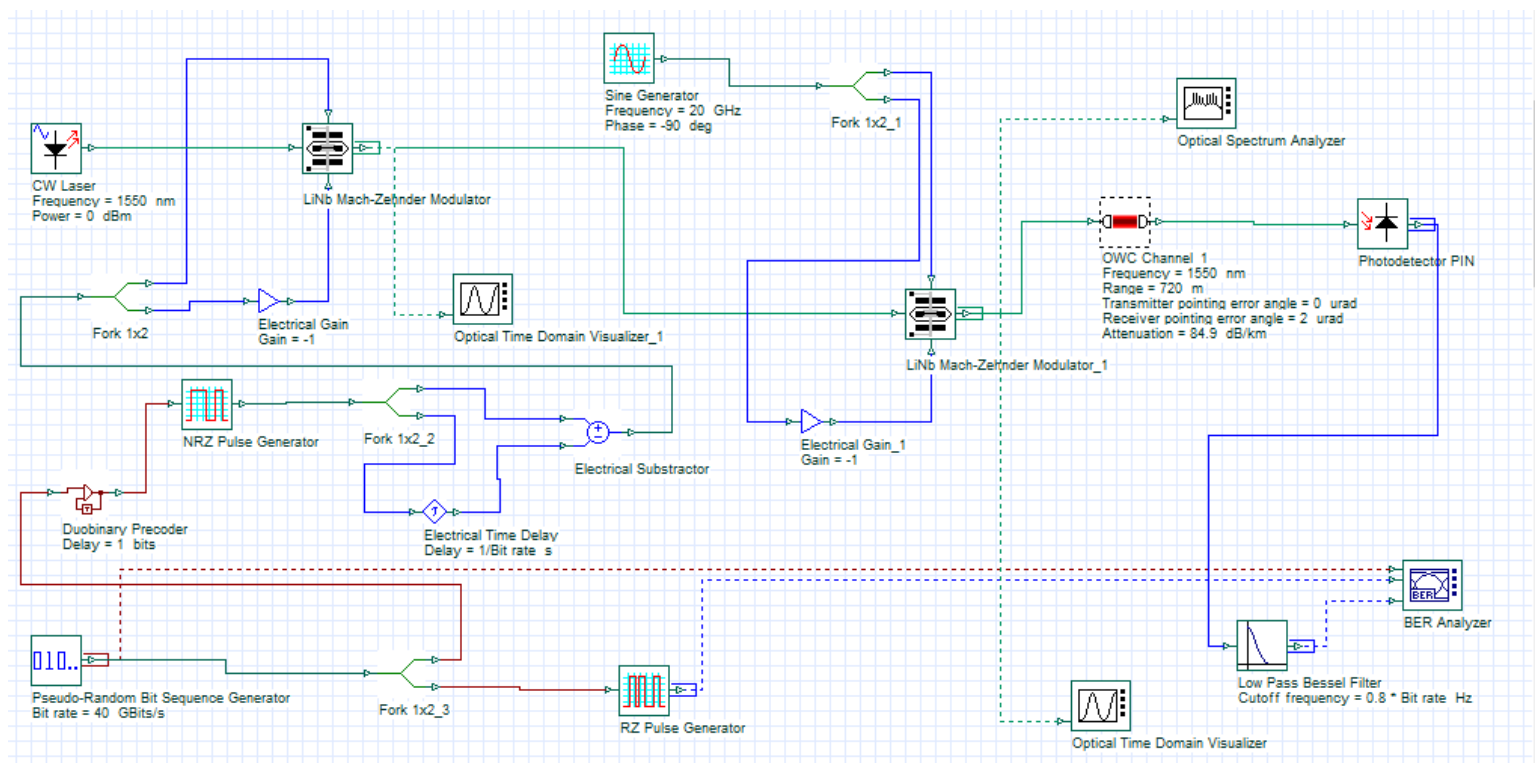

Figure 5. Block diagram of single channel OWC-MDRZ in optisystem program

The transmitter must contain a pseudo-random bit sequence (PRBS) generator that supplies our first signal to the fork 1 with a $1 * 2$ port. The fork divides the signals to two outputs, On the first output of the 
fork1, the output inter RZ pulse generates then goes to the final BER analyzer to synchronize the final output signal. Second exit of the fork1 is consider the major route un our system that feeds the duobinary procedure (with delay equal to 1 bits). Now the signal in the main course, the duobinary procedure need to shape these pulses by intering it in NRZ pulse generators. After that the output goes to the fork 2 that divide the signal into two sides, one of them inter directly to electrical subtractor and the other pass through the electrical time delay (with $1 /$ bit rates) then inter to the electrical subtractor.

The electrical subtractor fed fork3, the first forks outputs go to Li-Nb MZ modulator_1 after passing through electrical gain. So, we have the first input in MZ modulator_1 then the second input with $1550 \mathrm{~nm}$ wavelength is came from the continuous wave laser and at last the third input came from fork3 straight. After this MZ modulator_1 the output is going to Li-Nb MZ modulator_2 which in turn has likewise three inputs.

His second and third input come from a sine generator which having a phase equal to $-\pi / 2$ and frequency equal to the bit rate. In this $\mathrm{Li}-\mathrm{Nb} \mathrm{MZ}$ modulator_2, phase is inverted in the pulses that were aroused by the existence of logic ' 1 ' in the former bit slot. An electrical signal generator with phase equal to $-90^{\circ}$ and $20 \mathrm{GHz}$ is coming directly from a sinusoidal and goes to Li-Nb MZ modulator_2 as a second input. And finally, a signal that pass through the electrical gain $(-1)$ and than goes to the sinusoidal to become the third input to Li-Nb MZ modulator_2. In case of regular duobinary we alternate the phase of bits " 1 " is only after a bit " 0 " shows, however, in case of MDRZ we change the phase between 0 and 180 degrees for the bits " 1 ". That is as shown in Figure 6.

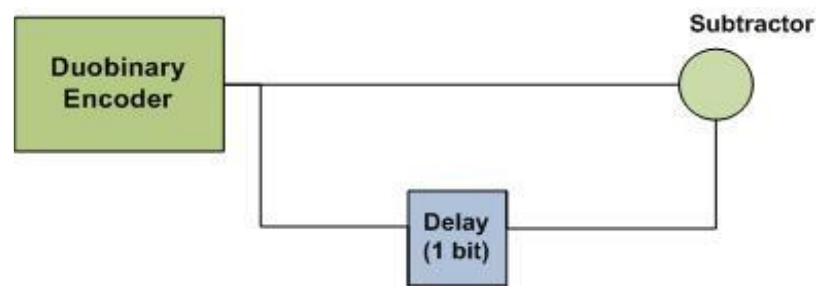

Figure 6. Generation of modified duobinary pulses

At the time we kept the phase "zero" bits to constant states, a $180^{\circ}$ phase different is inserted among all the sequential "ones" that end to extinction of the duobinary carrier signal. It is easy and therefore the Mach-Zehnder modulator (MZM) should be biased at the null point for direct detection. MDB pulses generation is done by transfer, combining of an extra delay. After that the output signal of the second Li-Nb MZ modulator_2 inter to the OWC transmitter through the atmosphere and then collect on the receiver side. The receiver contains decision-making unit, the detector and the receiver aperture. The aperture size defines the general value of gathering power, collecting the light coming within a specific radial range of the optic axis of transmission. For direct detection utilizing a personal identification number (PIN) photo detector that transforms the optical beam to an electrical signal which is then amplified. An optical low pass filter is generally set up after to the PIN photodetector to limit the background noise.

\section{RESULTS AND DISCUSSION}

In this partition, we presented a simulation result. The figures below indicate the graphs between distance and BER obtained for haze and fog in different attenuation level starting for $(84.9,25.5,15.5,2.37$, 0.55) $\mathrm{dB}$, which represent dense fog, heavy fog, light fog, heavy haze and light haze respectively. We measure each weather condition using 5 different values of pointing error $(2,4,6,8,10)$ urmd, monitor each one of them gave us an integrated scenario to different weather and pointing error, which is simulated a twobuilding connecting to each other in different time of the year and different location (especially the area in earthquake) the appropriate result to be analyzed.

From Figure 7 the results show that in case of light haze, BER value decreases as the attenuation decrease for the same transmission distance. From the Figure 8, it is obvious that at a range of $34 \mathrm{~km}$, in case of pointing error 2 is the best distance to cover. Where is $5 \mathrm{~km}$ in PE 10 is the best distance to cover. The value of the BER for heavy haze, light fog, heavy fog and dense fog at different distance is more than light haze and cover less distance, but identical when it come to the best pointing error, where is the 2 is always the best followed by 4, 6, 8, 10 .

As shown in Figure 8 the heavy haze can cover up to $15 \mathrm{~km}$ with PE 2 and $2.2 \mathrm{~km}$ with PE 10. For general information the cover meaning that the signal can reach the destination with acceptable effusion which mean 1e-12 for BER and 6 for Q-factor. As shown in the Figures 9, 10 and 11 the fog side the

Fog attenuation penalty analysis in terrestrial optical wireless communication-modified ... (Mustafa H. Ali) 
maximum distance to cover is $(2500,1750,630)$ meter with PE 2 and minimum distance to cover is $(800$, $600,275)$ meter with PE 10 for light fog, heavy fog and dense fog respectively.

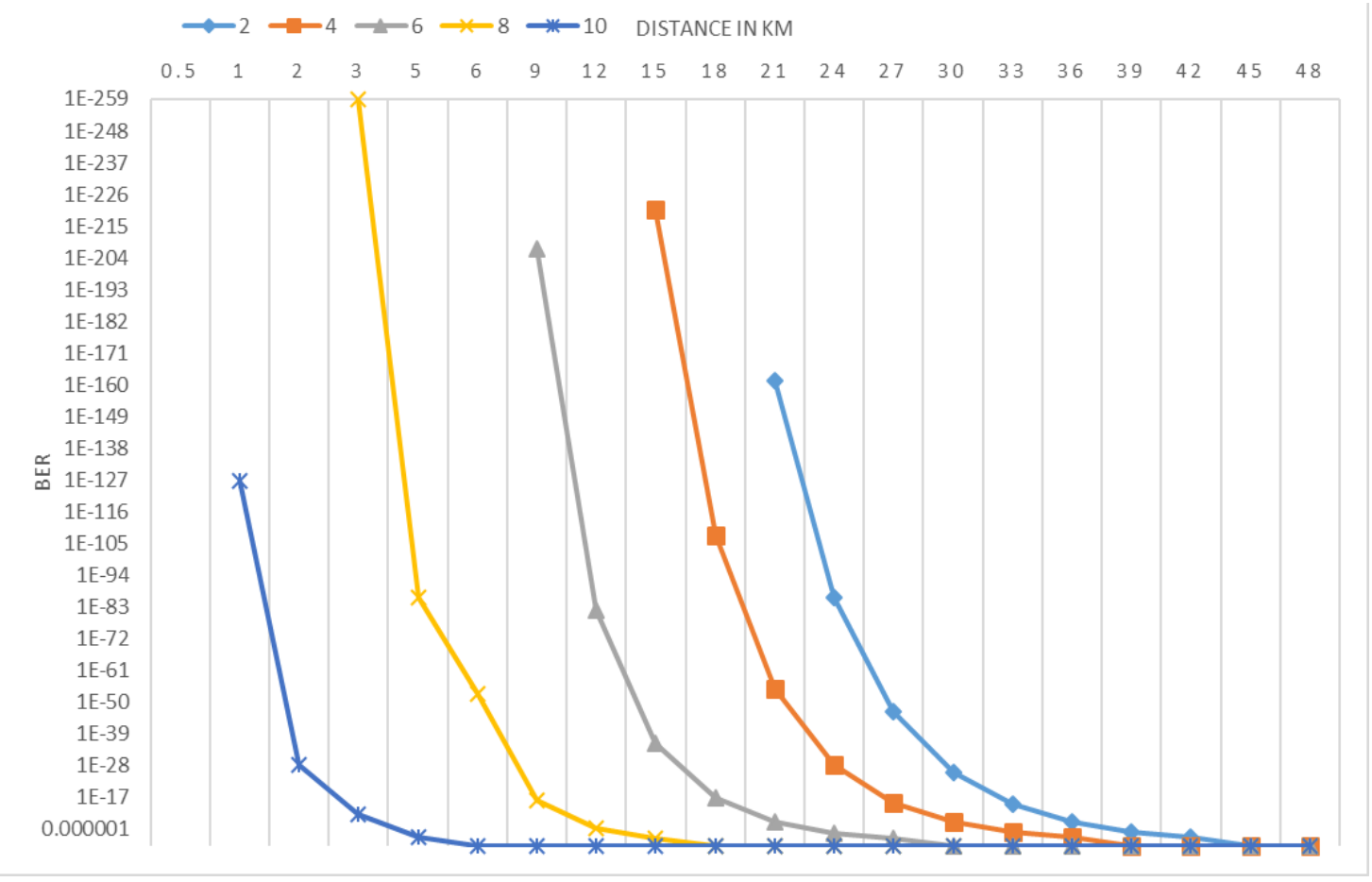

Figure 7. Shows a simulation result of OWC-MDRZ with various pointing error under light haze $(0.55) \mathrm{dB}$

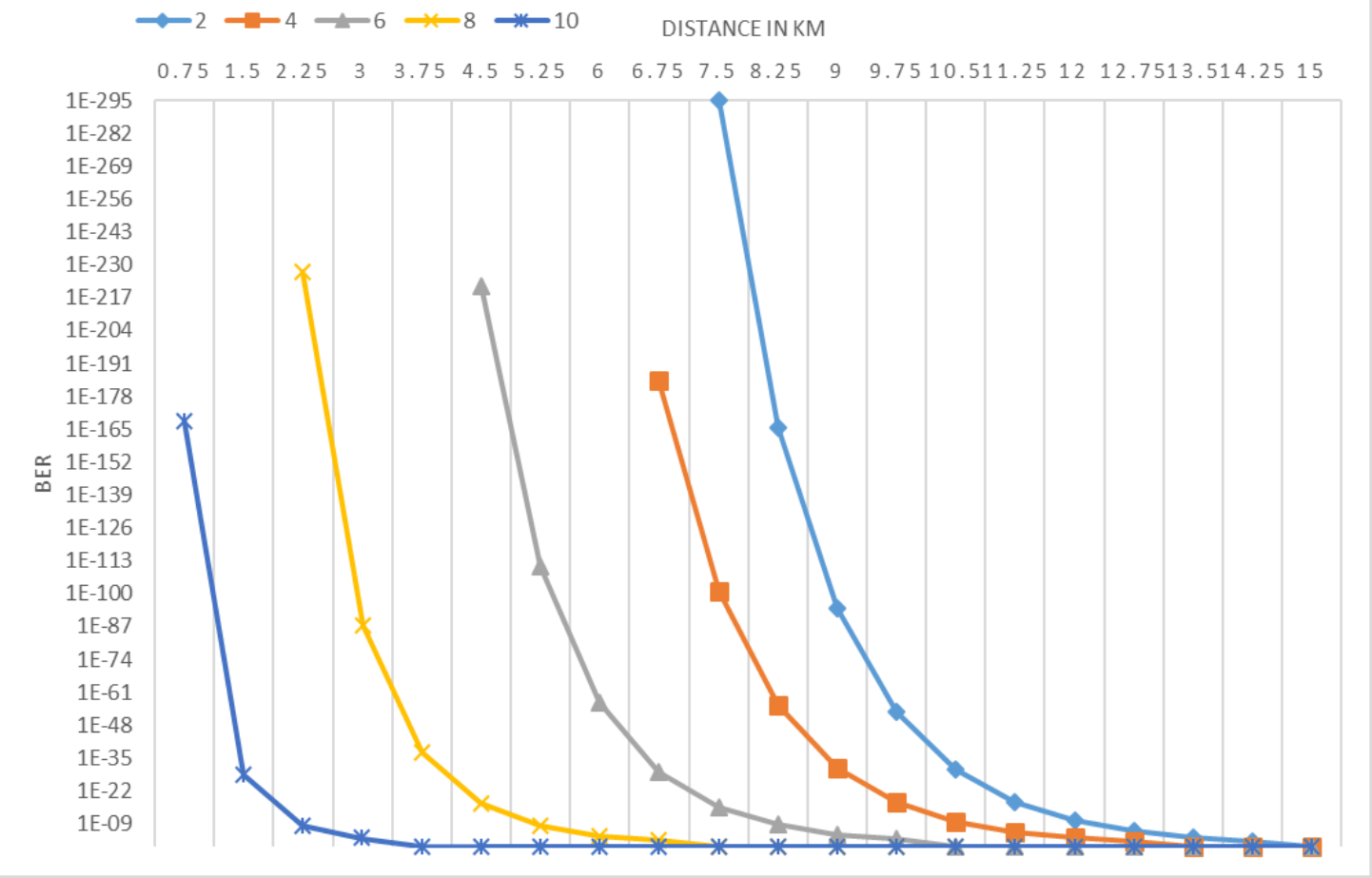

Figure 8. Shows a simulation result of OWC-MDRZ with various pointing error under heavy haze (2.37) dB 


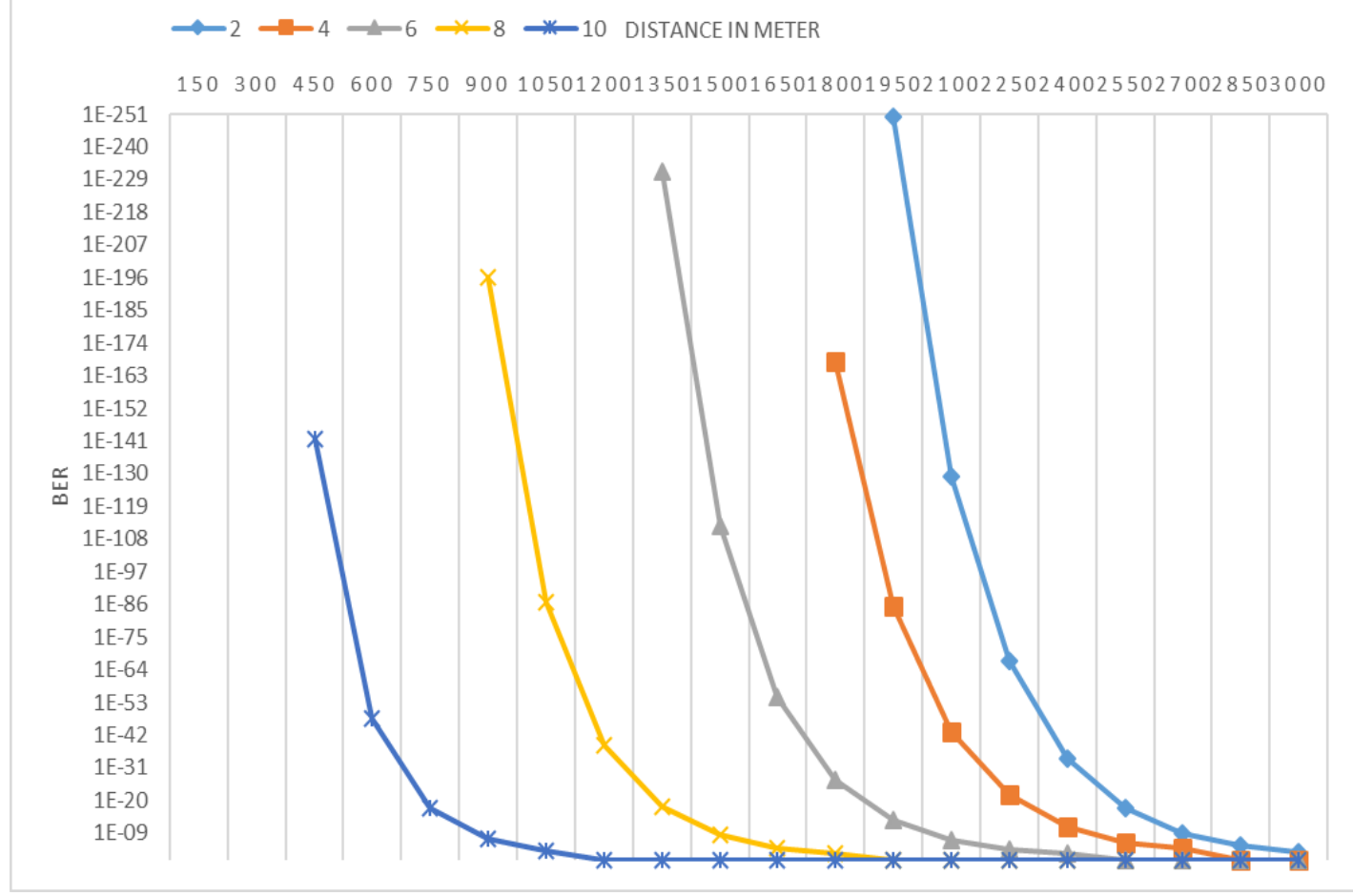

Figure 9. Shows a simulation result of OWC-MDRZ with various pointing error under light fog (15.5) dB

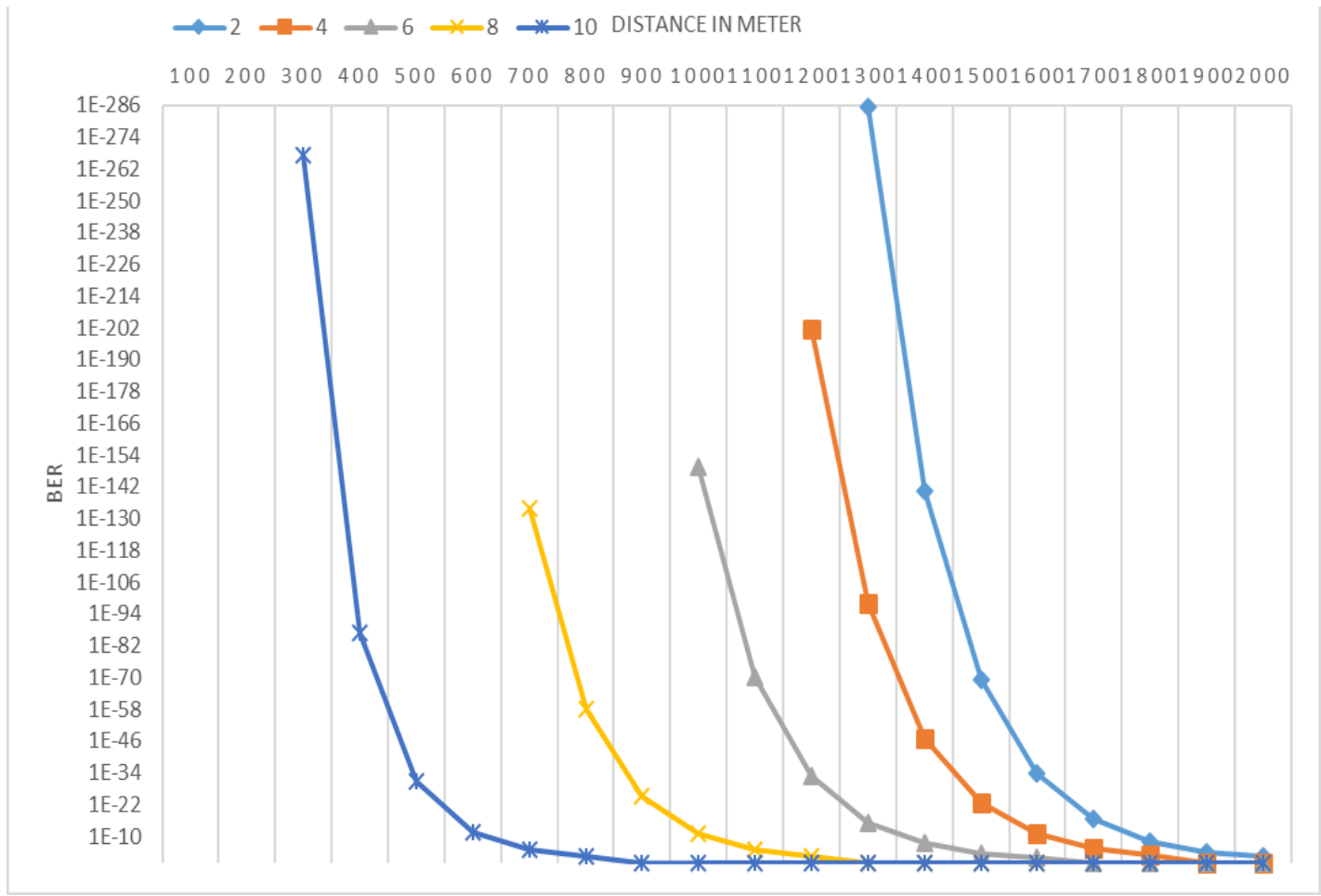

Figure 10. Shows a simulation result of OWC-MDRZ with various pointing error under heavy fog (25.5) dB 


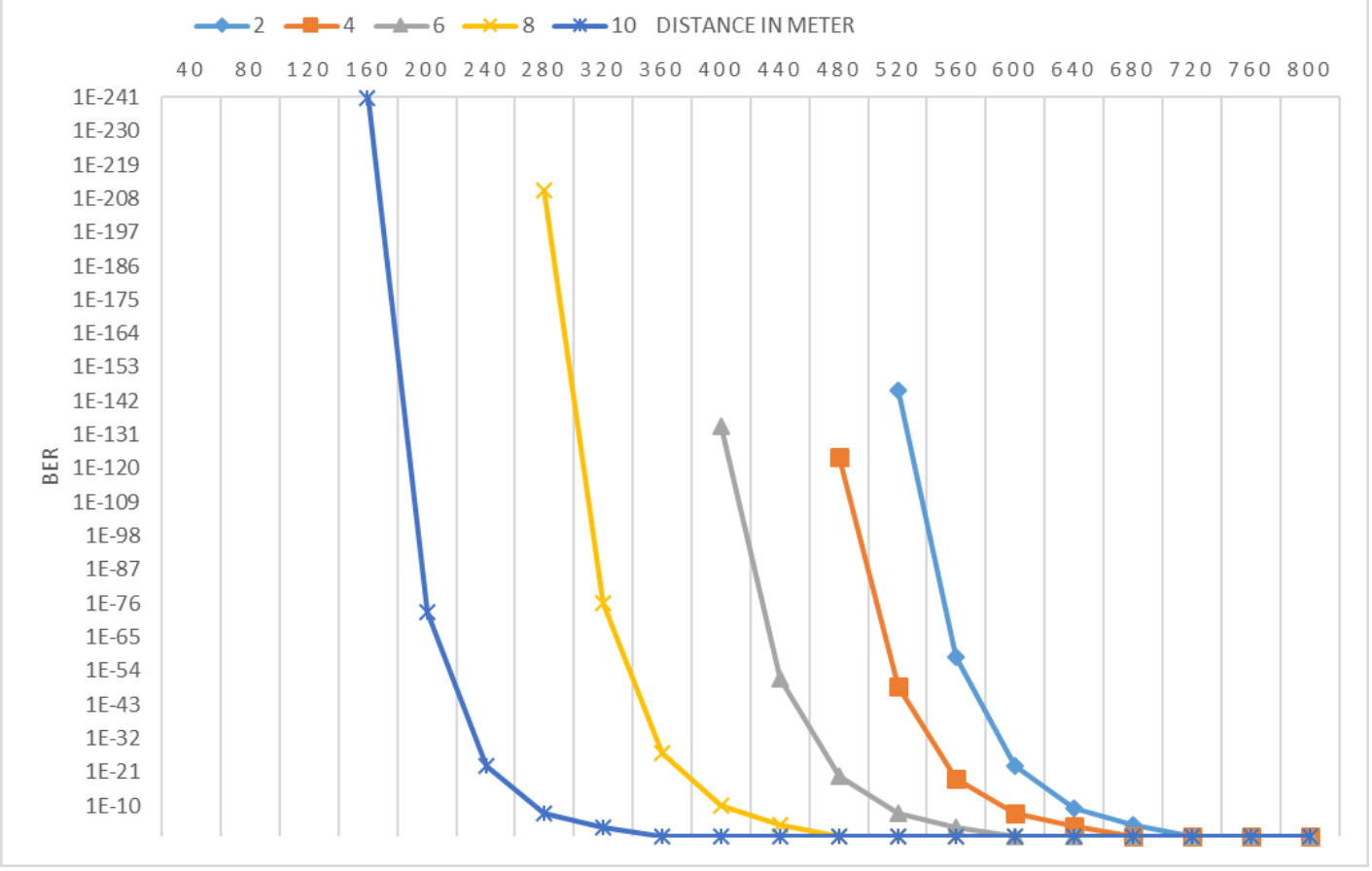

Figure 11. Shows a simulation result of OWC-MDRZ with various pointing error under dense fog (84.9) dB

We focus on the particular problem of haze and fog in the atmospheric channel, gas molecules and aerosols infiltrate this transition medium and minimize communication effectiveness even on a clear day. Because of scattering and absorption mechanisms. In our sample, the optical depth is the element which denotes the thickness of fog. In another word during the optical depth a multiple-scatter channel are commonly denoted the average number of interactions that light will incur when spreading.

From the figures above as the distance of the FSO raises, the value of receiving power decrease. The system's link range and performance are adversely affected in the time heavy haze and moderately in system simulation conditions on the other hand. The light haze displays the best result (maximum distance to cover) as compared to other weather conditions. Similarly, the value of SNR accomplished is higher in situation like light haze followed by heavy haze, light fog, heavy fog and dense fog. However, when transmitter-receiver alignment is not stringent maintained a narrow FOV receiver is becoming a very big problem.

\section{CONCLUSION}

In this work, $20 \mathrm{Gbps}$ Terrestrial-OWC MDRZ link is transported over the influence of weather turbulences using various transmitting pointing errors (PE). PE which plays a significant role with FOV restrictions due to it is the main problem when data transmission through a multi-scattering medium (haze or fog). The incident receiver power reduces not only the spatial spread and light attenuated absorption, but also by diffusion of the angle of arrival signal in the receiver aperture. This present work aims to analyze the interrelation between multiple scattering (light haze, heavy haze, light fog, heavy fog and dense fog) and receiver pointing error. We conclude from the result that the pointing error caused by beam wander is the predominant factor and it sorely decreases the SNR, link margin and raise the BER, when there is an increasing the turbulence strength and the track length. Our paper contributions are to avoid an unsuitable system that outcome from pointing errors and lost the scattered light that traverses the optic path. We recommended to guarantee transmitter-receiver alignment by installing a variable FOV receiver (a tracking system) to contribute in the scattering overcoming impact of the fog that make render urban laser communication effective in the presence of pointing error.

\section{ACKNOWLEDGEMENTS}

The authors would like to thank Mustansiriyah University (www.uomustansiriyah.edu.iq) BaghdadIraq for it is support in the present work. 


\section{REFERENCES}

[1] N. Kumar, "Enhanced performance analysis of inter-satellite optical-wireless communication (IsOWC) system," Optik, vol. 125, no. 8, pp. 1945-1949, Apr. 2014, doi: 10.1016/j.ijleo.2013.11.008.

[2] M. Singh, "Simulative Investigation on the Effect of Different Parameters on the Performance of IsOWC System," Journal of Optical Communications, vol. 38, no. 3, Jan. 2017, doi: 10.1515/joc-2016-0058.

[3] M. Singh, "Enhanced Performance Analysis of Inter-aircraft Optical Wireless Communication Link (IaOWC) Using EDFA Preamplifier," Wireless Personal Communications, vol. 97, no. 3, pp. 4199-4209, Jul. 2017, doi: 10.1007/s11277-017-4720-3.

[4] A. W. Y. Khang, S. J. Elias, J. Pusppanathan, N. Zulkifli, N. H. Halim, and S. Abdullah, "Last mile mobile hybrid optical wireless access network routing enhancement," Bulletin of Electrical Engineering and Informatics, vol. 8, no. 1, pp. 188-195, Mar. 2019, doi: 10.11591/eei.v8i1.1434.

[5] E. Zedini, A. Chelli, and M. Alouini, "On the Performance Analysis of Hybrid ARQ With Incremental Redundancy and With Code Combining Over Free-Space Optical Channels with Pointing Errors,” in IEEE Photonics Journal, vol. 6, no. 4, pp. 1-18, Aug. 2014, Art no. 7902118, doi: 10.1109/JPHOT.2014.2339331.

[6] P. Kaur, V. K. Jain, and S. Kar, "Performance analysis of free space optical links using multi-input multi-output and aperture averaging in presence of turbulence and various weather conditions," IET Communications, vol. 9, no. 8, pp. 1104-1109, May 2015, doi: 10.1049/iet-com.2014.0926.

[7] N. Shaik and P. K. Malik, "A Retrospection of Channel Estimation Techniques for 5G Wireless Communications: Opportunities and Challenges," International Journal of Advanced Science and Technology, vol. 29, no. 05, pp. 8469-8479, May 2020.

[8] P. Malik, D. S. Wadhwa, and J. S. Khinda, "A Survey of Device to Device and Cooperative Communication for the Future Cellular Networks," Int J Wireless Inf Networks, vol. 27, pp. 411-432, Feb 2020, doi: 10.1007/s10776-020-00482-8.

[9] P. K. Malik and H. Parthasarthy, "Synthesis of randomness in the radiated fields of antenna array," International Journal of Microwave and Wireless Technologies, vol. 3, no. 6, pp. 701-705, Oct. 2011, doi: 10.1017/s1759078711000791.

[10] M. M. A. Eid and A. N. Z. Rashed, "Hybrid NRZ/RZ line coding scheme based hybrid FSO/FO dual channel communication systems," Indonesian Journal of Electrical Engineering and Computer Science, vol. 22, no. 2, pp. 866-873, May 2021, doi: 10.11591/ijeecs.v22.i2.pp866-873.

[11] A. Rahim, P. K. Mallik, and V. A. S. Ponnapalli, "Fractal Antenna Design for Overtaking on Highways in 5G Vehicular Communication Ad-hoc Networks Environment," International Journal of Engineering and Advanced Technology (IJEAT), vol. 9, no. 1S6, pp. 157-160, Dec 2019, doi: 10.35940/ijeat.A1031.1291S619.

[12] B. Flecker, M. Gebhart, E. Leitgeb, S. Sheikh Muhammad, and C. Chlestil, "Results of attenuation-measurements for Optical Wireless Channel under dense fog conditions regarding different wavelengths," Proc. SPIE, Sep. 2006, doi: 10.1117/12.680456.

[13] A. J. Mahdi, W. J. Mazher, and O. N. Ucan, "Impact of pointing error on SISO/MISO drones swarm-based free space optical system in weak turbulence regime," Indonesian Journal of Electrical Engineering and Computer Science, vol. 23, no. 2, pp. 918-926, Aug. 2021, doi: 10.11591/ijeecs.v23.i2.pp918-926.

[14] H. Saidi and N. Hamdi, "End-to-end performance of DF multihop hybrid RF/FSO system using MPPM coding and MIMO technique under dependent GG turbulence channels," Indonesian Journal of Electrical Engineering and Computer Science, vol. 19, no. 2, pp. 811-818, 2020, doi: 10.11591/ijeecs.v19.i2.pp811-818.

[15] M. C. Al Naboulsi, H. Sizun, and F. de Fornel, "Fog Attenuation Prediction for Optical and Infrared Waves," Optical Engineering, vol. 43, no. 2, pp. 319-329, Feb. 2004, doi: 10.1117/1.1637611.

[16] M. F. Talib, M. S. Auar, and C. B. M. Rashidi, "Performance of geometrical effect in wavelength filtrate detection using 10gbps data rate for free space optical communication system," Indonesian Journal of Electrical Engineering and Computer Science, vol. 13, no. 2, pp. 575-583, Feb. 2019, doi: 10.11591/ijeecs.v13.i2.pp575-583.

[17] D. S. Ilcev, "Development of stratospheric communication platforms (SCP) as backbone to terrestrial networks," Indonesian Journal of Electrical Engineering and Computer Science, vol. 18, no. 3, pp. 1679-1688, Jun. 2020, doi: 10.11591/ijeecs.v18.i3.pp1679-1688.

[18] M. Singh, "Mitigating the effects of fog attenuation in FSO communication link using multiple transceivers and EDFA," J. Opt. Commun, vol. 38, no. 2, pp. 169-174, July 2016, doi: 10.1515/joc-2016-0061

[19] M. S. Awan, E. Leitgeb, F. Nadeem, M. S. Khan, and C. Capsoni, "A New Method of Predicting Continental Fog Attenuations for Terrestrial Optical Wireless Link,” 2009 Third International Conference on Next Generation Mobile Applications, Services and Technologies, 2009, pp. 245-250, doi: 10.1109/NGMAST.2009.31

[20] A. K. Rahman et al., "Spectral coding performance under free space optical medium," Indonesian Journal of Electrical Engineering and Computer Science, vol. 14, no. 1, pp. 290-294, Apr. 2019, doi: 10.11591/ijeecs.v14.i1.pp290-294.

[21] A. H. Ali, H. J. Alhamdane, and B. S. Hassen, "Design analysis and performance evaluation of the WDM integration with COOFDM system for radio over fiber System," Indonesian Journal of Electrical Engineering and Computer Science, vol. 15, no. 2, pp. 870-878, Aug. 2019, doi: 10.11591/ijeecs.v15.i2.pp870-878.

[22] J.-S. Lee, D.-H. Lee, S.-J. Kim, and C.-H. Oh, "An LED-based visible light communication system for multicast," Indonesian Journal of Electrical Engineering and Computer Science, vol. 13, no. 1, pp. 265-271, Jan. 2019, doi: 10.11591/ijeecs.v13.i1.pp265-271.

[23] M. Abaza, R. Mesleh, A. Mansour, and A. El-Hadi, "Performance analysis of MISO multi-hop FSO links over log-normal channels with fog and beam divergence attenuations," Optics Communications, vol. 334, pp. 247-252, Jan. 2015, doi: 10.1016/j.optcom.2014.08.050.

[24] V. Sharma and N. Kumar, "Modeling of 2.5 Gbps-intersatellite link (ISL) in inter-satellite optical wireless communication (IsOWC) system,” Optik, vol. 124, no. 23, pp. 6182-6185, Dec. 2013, doi: 10.1016/j.ijleo.2013.04.094.

[25] F. Hossain, "Impact of travelling wave semiconductor optical amplifier on WDM-FSO system under fog attenuation," Int $J$ Sci Res, vol. 3, no. 4, pp. 235-238, 2014

[26] M. Ijaz, Z. Ghassemlooy, J. Pesek, O. Fiser, H. Le Minh, and E. Bentley, "Modeling of Fog and Smoke Attenuation in Free Space Optical Communications Link Under Controlled Laboratory Conditions," in Journal of Lightwave Technology, vol. 31, no. 11, pp. 1720-1726, Jun. 2013, doi: 10.1109/JLT.2013.2257683.

[27] R. S. Misbakhov et al., "Address fiber optical sensor for relative humidity measuring in a switchgear," Optical Technologies for Telecommunications, May 2020, doi: 10.1117/12.2566525.

[28] Sawhil, S. Agarwal, Y. Singhal, and P. Bhardwaj, “An Overview of Free Space Optical Communication,” International Journal of Engineering Trends and Technology (IJETT), vol. 55, no. 3, pp. 120-125, 2018, doi: 10.14445/22315381/IJETT-V55P223.

[29] A. G. W. G. Wadday, F. M. Ali, and H. J. M. Albattat, "Design of high scalability multi-subcarrier RoF hybrid system based on optical CDMA/TDM," Indonesian Journal of Electrical Engineering and Computer Science, vol. 21, no. 2, pp. 927-937, 2021, doi: 10.11591/ijeecs.v21.i2.pp927-937. 
[30] K. A. Balaji and K. Prabu, "Optics CommunicationsBER analysis of relay assisted PSK with OFDM ROFSO system over Malaga distribution including pointing errors under various weather conditions," Optics Communications, vol. 426, pp. 187-1931, 2018, doi: 10.1016/j.optcom.2018.05.027.

[31] F. Ebrahimi, G. Baghersalimi, and Z. Ghassemlooy, "Comparison of Hybrid DCO-OFDM-PWM and DCO-OFDM-PPM Schemes in Cellular Channel," Physics, 2018.

[32] F. Ebrahimi, Z. Ghassemlooy, and S. Olyaee, "Investigation of a hybrid OFDM-PWM/PPM visible light communications system," Optics Communications, vol. 429, pp. 65-71, Dec. 2018, doi: 10.1016/j.optcom.2018.08.001.

[33] D. Kedar and S. Arnon, "Optical wireless communication through fog in the presence of pointing errors," Optical Society of America, vol. 42, no. 24, pp. 4946-4954, 2003, doi: 10.1364/AO.42.004946.

[34] S. S. Muhammad, B. Flecker, E. Leitgeb, and M. Gebhart, "Characterization of fog attenuation in terrestrial free space optical links," Optical Engineering, vol. 46, no. 6, Jun. 2007, doi: 10.1117/1.2749502.

[35] H. K. Gill, N. S. Grewal, and G. K. Walia, "Comparative investigation of CSRZ-DQPSK, DRZ-DQPSK, and MDRZ-DQPSK modulation techniques in MDM IS-OWC system," Microwave and Optical Technology Letters, vol. 61, no. 7, pp. 1802-1809, Feb. 2019, doi: 10.1002/mop.31807.

[36] N. A. Androutsos, H. E. Nistazakis, W. Gappmair, A. N. Stassinakis, and G. S. Tombras, "Pointing errors influence at the performance of a multi-hop terrestrial FSO link emulated by a dual-hop scheme," Optics Communications, vol. 475, Nov. 2020, doi: 1016/j.optcom.2020.126223.

[37] W. Gappmair and H. E. Nistazakis, "Subcarrier PSK Performance in Terrestrial FSO Links Impaired by Gamma-Gamma Fading, Pointing Errors, and Phase Noise," in Journal of Lightwave Technology, vol. 35, no. 9, pp. 1624-1632, May, 2017, doi: 10.1109/JLT.2017.2685678.

[38] S. Chauhan, R. Miglani, L. Kansal, G. S. Gaba, and M. Masud, "Performance Analysis and Enhancement of Free Space Optical Links for Developing State-of-the-Art Smart City Framework," Photonics, vol. 7, no. 4, Dec. 2020, doi: 10.3390/photonics7040132.

\section{BIOGRAPHIES OF AUTHORS}

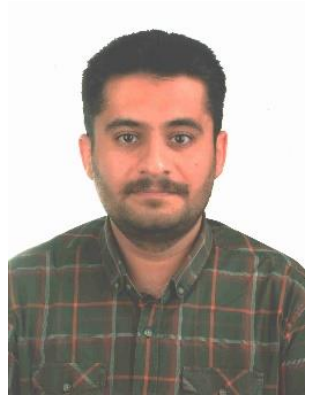

Mustafa H. Ali (D) If SC P was born in Baghdad, Iraq, in 1990. He received the B.S. degree from Middle Technical University (MTU), Baghdad, Iraq in 2012, in specialty Computer Technical Engineering and the M.S. degree from Kazan State Technical University (named after A. N. Tupolev) Kazan, Russia in 2016, In specialty Info-communication technology and communication systems. He is currently working as a lecturer at Department of Basic Sciences/College of Dentistry/Mustansiriyah University. His research interests include Optical Communication Engineering, Passive Optical Network, Radio Over Fiber and Optical Wireless Communications. He can be contacted at email: mustafa.h@uomustansiriyah.edu.iq.

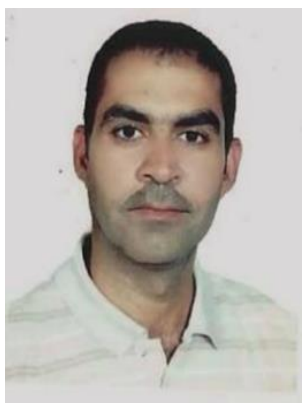

Dr. Tariq A. Hassan (D) SC S P was born in Baghdad, Iraq, in 1976. He received the B.S. degree from ALRafidain University, Baghdad, Iraq, in 2000, in specialty Computer Science and the M.S. degree from Al-Mustansiriyah University, collage of Sceince, Baghdad, Iraq, in 2005., In specialty Digital signal processing (DSP). Ph.D. degree is received from Southampton University in computer science, UK in 2012. He is currently working as a lecturer at Department of Computer Sciences /College of Education/Mustansiriyah University. His research interest's robust speaker identification and verification, speaker recognition, Speech compression and hiding. Signal analysis and chaotic technique application. He can be contacted at email: tariqmono2016@uomustansiriyah.edu.iq.

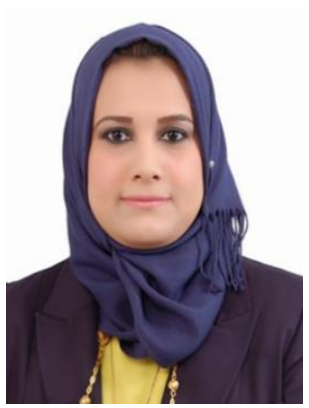

Hiba A. Abu-Alsaad (iD I8 SC P was born in Baghdad, Iraq, in 1983. She received the B.S. degree from the University of Mustansiriyah of Iraq, Baghdad, in 2005 and the M.S. degree from the University of Politehnica (UPB), Bucharest, in 2016, both in Computer \& Software Engineering. She is working as a Lecturer at the Computer Engineering Department/Collage of Engineering, Mustansiriyah University, Baghdad-Iraq. She can be contacted at email: Eng.hibaakram@uomustansiriyah.edu.iq. 